\title{
COVID-19: The daunting experience of healthcare workers in Sardinia, Italy
}

\author{
Saverio Bellizzi $\mathrm{PhD}^{1}$ (1), Maura Fiamma $\mathrm{PhD}^{2}$, Luigi Arru MD², Gabriele Farina $\mathrm{MD}^{3}$ and Antonio Manca $\mathrm{PhD}^{4}$ \\ ${ }^{1}$ Independent Medical Epidemiology Consultant, Geneva, Switzerland, ${ }^{2}$ Polo Ospedaliero San Francesco, ASSLL, Nuoro, Italy, ${ }^{3}$ Independent Neurology Consultant, \\ Sassari, Italy and ${ }^{4}$ Candiolo Cancer Institute FPO, IRCCS, Italy
}

To the Editor-SARS-CoV-2, like other emerging high-threat pathogens, has infected health-care workers (HCWs) in China and several other countries. However, where the infection prevention and control strategies were strictly taken, nosocomial transmission has not been a major amplifier of transmission in this pandemic. ${ }^{1}$ As of early March, the National Health Commission of China indicated that $>3,300$ HCWs had been infected (of whom 22 died). ${ }^{2}$

In Italy, HCW infections make up 9.0\% of Italy's COVID-19 cases, ${ }^{3}$ which represents a serious concern because HCWs who are infected, if identified by a proper test, must stay away from healthcare facilities for at least 14 days, depleting the already exhausted workforce.

Major disparities exist across regions in Italy: by the end of the third epidemiological week of March 2020, of the 176 notified COVID-19-positive patients in Sardinia, 69 (39.2\%) were HCWs, ${ }^{4}$ which is a striking finding when compared with the national average. In the same period, the largely hit Lombardy region recorded 3,957 affected HCWs of a total 28,750 cases (13.8\%). ${ }^{4}$

During the fourth epidemiological week of March, the 3 major Labor Unions (CGIL, CISL, and UIL) suggested that the percentage of HCWs infected was $\sim 50.0 \%$ of the total. Proportions soared in the province of Sassari, where 6 of 10 new cases were HCWs. ${ }^{5}$ On the other hand, the most recent biweekly national epidemiological report indicates that $200 \mathrm{HCWs}$ of 490 total persons tested in Sardinia were positive for SARS-CoV-2. ${ }^{6}$

Such figures refer to something of unique relevance at the international level during this pandemic, and they align with findings from small outbreaks in Marburg and from Ebola virus outbreaks in which the nonendemic disease was suddenly introduced by an isolated traveler or individual. ${ }^{7}$

Sassari is one of the few European settings that witnessed a case of Ebola during the large 2014 West African epidemic. ${ }^{8}$ This event led to the implementation of a preparedness plan in line with international standards, with great emphasis on the use of PPE and appropriate protocols for the protection of health personnel.

Conversely, during this COVID-19 epidemic, PPE shortages have been described in several affected facilities, and some medical staff are waiting for equipment while already seeing patients who may be infected or are supplied with equipment that might not meet requirements.

Sardinia island has some geographical and demographical peculiarities that should have been taken into account. Even if

Author for correspondence: Saverio Bellizzi, PhD, 20 Avenue Appia 1211, Geneva, Switzerland, E-mail: Saverio.bellizzi@gmail.com

Cite this article: Bellizzi S, et al. (2020). COVID-19: The daunting experience of healthcare workers in Sardinia, Italy. Infection Control \& Hospital Epidemiology, 41: 1118-1119, https://doi.org/10.1017/ice.2020.149 it is the second largest island in Mediterranean sea and the third largest Italian region by surface ranking (ie, bigger than Lombardy), it has 1.66 million inhabitants with a population density of 69 inhabitants per square kilometer, which that is the third lowest in Italy and far lower than that of Lombardy (ie, 422 inhabitants per square kilometer). Insularity could be an advantage during the pandemic, but notably, the current global epidemic started in late December 2019, which should have provided ample time to prepare well.

Also, many people from northern Italy moved to the island, filling up holiday houses before the government's resolution to reduce and control air and naval transportation. Only 11,000 people reported for quarantine, and the number of unreported immigrants is unknown. ${ }^{9}$ Such a large number of people coming from a "red zone," could have led to a sudden increase in COVID-19 cases.

Given the ongoing severe situation in Lombardy, with $>300$ deaths per day in 27 April 2020, a similar trend coupled with nosocomial spread of SARS-CoV-2 among HCWs in Sardinia might have huge consequences for the local population. Physical and mental exhaustion, the pain of losing patients and colleagues, the fear of passing the infection to their families, and the torment of difficult triage decisions have intensified a very difficult situation.

Preparedness for the ongoing coronavirus disease calls for setting up of adequately equipped health facilities while protecting HCWs, which are every country's most valuable resource. Practical measures, such as adequate provision of PPE, protocols, and continuous programs of education and training in PPE donning and doffing, should be considered a priority to ensure the safety of HCWs in current and future outbreaks.

New infections continue to emerge, and this constant threat urgently requires a cultural shift toward preparedness.

\section{Acknowledgments.}

Financial support. No financial support was provided relevant to this article.

Conflicts of interest. All authors report no conflicts of interest relevant to this article.

\section{References}

1. Bedford J, Enria D, Giesecke J, et al. COVID-19: towards controlling of a pandemic. Lancet 2020 Mar 17 [Epub ahead of print]. doi: 10.1016/S01406736(20)30673-5.

2. COVID-19: protecting healthcare workers. Lancet 2020;395:922.

3. High proportion of healthcare workers with COVID-19 in Italy is a stark warning to the world: protecting nurses and their colleagues must be the number one priority. International Council of Nurses website. https://www.

(c) 2020 by The Society for Healthcare Epidemiology of America. All rights reserved. This is an Open Access article, distributed under the terms of the Creative Commons Attribution licence (http://creativecommons.org/licenses/by/4.0/), which permits unrestricted re-use, distribution, and reproduction in any medium, provided the original work is properly cited. 
icn.ch/news/high-proportion-healthcare-workers-covid-19-italy-stark-warningworld-protecting-nurses-and. Published March 2020. Accessed March 30, 2020.

4. Istituto Superiore di Sanita'. Sorveglianza integrata COVID-19 in Italia [in Italian]. Epicentro website. https://www.epicentro.iss.it/coronavirus/bollettino/ Bolletino-sorveglianza-integrata-COVID-19_23-marzo-2020_appendix. pdf. Published March 23, 2020. Accessed March 30, 2020.

5. Boom di contagi tra medici e infermieri sardi: "Il 50\%, il 90\% a Sassari" [in Italian]. L'UNIONE SARDA website. https://www.unionesarda.it/articolo/newssardegna/cagliari/2020/03/22/in-sardegna-e-boom-di-contagi-tra-medici-einfermieri-il-50-il-90-136-1000398.html. Published March 22, 2020. Accessed March 30, 2020.

6. Istituto Superiore di Sanita'. Sorveglianza integrata COVID-19 in Italia [in Italian]. Epicentro website. https://www.epicentro.iss.it/coronavirus/bollettino/
Bolletino-sorveglianza-integrata-COVID-19_30-marzo-2020_appendix. pdf. Published March 30, 2020. Accessed March 31, 2020.

7. Selvaraj SA, Lee KE, Harrell, et al. Infection rates and risk factors for infection among health workers during Ebola and Marburg virus outbreaks: a systematic review. J Infect Dis 2018; 218 suppl 5:S679-S689.

8. Bertoli G, Mannazzu M, Madeddu G, et al. Ebola virus disease: case management in the Institute of Infectious Diseases, University Hospital of Sassari, Sardinia, Italy. J Infect Dev Cntries 2016;10:537-543.

9. Dal Nord rientrano in Sardegna: in 11 mila si "autodenunciano" [in Italian]. L'UNIONE SARDA website. https://www.unionesarda.it/articolo/news-sard egna/cagliari/2020/03/11/dal-nord-alla-sardegna-in-11mila-si-autodenunciano136-996411.html. Published March 11, 2020. Accessed March 30, 2020.

\title{
The importance of initial response during outbreaks: A perspective from observations on COVID-19
}

\author{
Yao Yu Yeo ${ }^{1}$ (1) and Bruce Ganem ${ }^{2}$ \\ ${ }^{1}$ Department of Microbiology and Immunology, Cornell University, Ithaca, New York and ${ }^{2}$ Department of Chemistry and Chemical Biology, Cornell University, \\ Ithaca, New York
}

To the Editor-Pandemics have occurred throughout history and have generally led to catastrophic aftermaths across all levels of society. Notable examples include the black death in the 14th century and the 1918 Spanish flu; both names strike like a universal apocalyptic chorus. ${ }^{1}$ Although the understanding of microbes, the emergence of epidemiology, and rapid advancement of science and medicine over the 19th and 20th centuries have kept many old pathogens at bay and have led to an unprecedented quality of life, ${ }^{2}$ the modern world has already faced 2 dangerous new pandemics (2009 H1N1 influenza and COVID-19) in the 21st century.

These recent pandemics are of particular concern not only because the medical and scientific communities were already aware of (and quite familiar with) both families of viruses but also because we currently live in an era that boasts stellar healthcare quality compared to just a century ago. For these reasons, the ongoing COVID-19 pandemic merits closer examination as a case study for learning new approaches to restraining future outbreaks.

The COVID-19 pandemic originated in Wuhan, China, in December 2019. ${ }^{3}$ It began as an epidemic but has since spread to $>150$ countries and sovereignties. ${ }^{4}$ Although some countries and sovereignties (eg, Singapore, Hong Kong, and Taiwan) have managed to contain the spread of SARS-CoV-2, others (eg, Italy, Spain, and the United States) have experienced an unexpected number of COVID-19 cases and are struggling with overburdened healthcare facilities despite the fact that all 6 of these countries (except Spain) quickly implemented travel restrictions to mainland China within the first week ${ }^{5}$ and executed domestic lockdowns to restrict community spread. However, a major difference that helps explain the disparity in the severity of the pandemic is evident in these countries' initial responses to COVID-19.

Author for correspondence: Yao Yu Yeo, E-mail: yy826@cornell.edu

Cite this article: Yeo YY and Ganem B. (2020). The importance of initial response during outbreaks: A perspective from observations on COVID-19. Infection Control \& Hospital Epidemiology, 41: 1119-1120, https://doi.org/10.1017/ice.2020.150
Three countries and sovereignties that have managed COVID19 remarkably well (Singapore, Hong Kong, and Taiwan) happen to be densely populated regions whose citizens frequently travel to and from mainland China, which makes their achievement noteworthy. Since the emergence of SARS-CoV-2, these countries and sovereignties have made testing widely available and accessible and have carried out rigorous contact tracing, thus facilitating the diagnosis and treatment of every case. Ministers in these countries have also been warning about the impending outbreak and relaying accurate information around the clock. Although they initially created panic, these efforts resulted in a perpetual minimal relative number of new cases over the past few months (Fig. 1). Today, Singapore, Hong Kong, and Taiwan enjoy a reassuring sense of social calm and security.

By contrast, 3 countries that currently face sharp increases of new cases each day (ie, Italy, Spain, and the United States) either delayed or lacked sufficient access to reliable testing for various reasons (Fig. 1). One critical difference in their initial approaches was the overall sense of complacency by government officials, resulting in a reactive instead of proactive response. Italy, Spain, and the United States chose to falsely reassure the populace and to downplay the threat of COVID-19. Dissemination of coherent information about the pandemic only began after more than 1 month (in Italy) ${ }^{6}$ and 1.5 months (in Spain), ${ }^{7}$ upon observing a surge in new COVID-19 cases (Fig. 1). By that time, the pandemic had grown out of control in those countries and had overwhelmed healthcare facilities. The number of new cases in Italy has stabilized recently, suggesting that aggressive actions are working, but the crisis could have been averted had the country chosen to handle COVID-19 diligently from the start and ensured that sufficient COVID-19 testing was conducted sooner. As a result, Italy, Spain, and the United States are among the many countries experiencing severe social and economic turmoil today.

A central takeaway from the COVID-19 experience in these 6 countries is the strong association between initial action and 